\section{Reconnecting "missing" part of duct by needle knife using rendezvous technique}

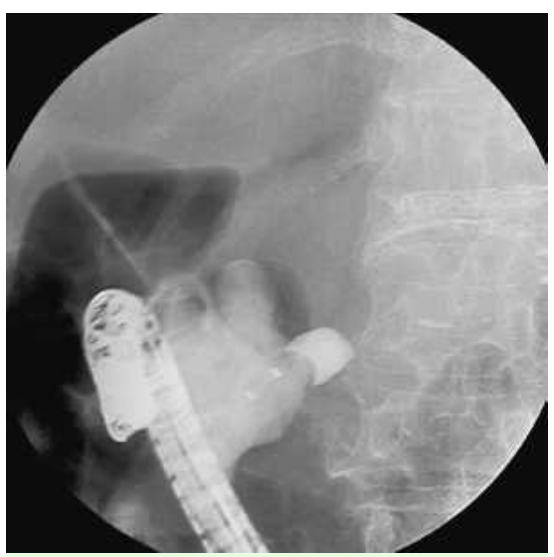

Fig. 1 Cut-off sign at the mid extrahepatic common bile duct.
A 73-year-old Thai woman presented with a recurrent episode of cholangitis. Two months previously, she had presented with acute cholangitis and underwent endoscopic retrograde cholangiopancreatography (ERCP) with sphincterotomy and balloon extraction for common bile duct stones. This time, a repeat ERCP was performed. Surprisingly, the cholangiogram showed a cut-off sign at the mid extrahepatic duct ( $\bullet$ Fig. 1). A CT scan of the abdomen showed air in the gallbladder, but no mass or cause of biliary obstruction was found ( $\bullet$ Fig. 2). The patient subsequently underwent percutaneous biliary drainage, and a cholangiogram confirmed the mid extrahepatic duct obstruction ( $\bullet$ Fig. 3 ). In addition, contrast extravasation from the gallbladder into the jejunum was observed. A third ERCP performed under the rendezvous technique demonstrated a thin area of disconnected common bile duct. An attempt to traverse the obstruction with a guide wire from both sides was unsuccessful. A triple-lumen needle knife (Microvasive, Natick, Massachusetts, USA) was introduced intraductally (๑ Fig.4). Under fluoroscopic guidance, a puncture was successfully made into the upstream disconnected duct ( Fig. 5). Finally, a 10-Fr plastic stent was inserted to bridge the duct ( Fig.6). The patient was discharged home within 2 days and reported no symptom that related to perforation or bleeding. Currently, she is rescheduled for repeat ERCP for stent upsizing.

Normally, rendezvous biliary drainage is led from the percutaneous site $[1,2]$. En-

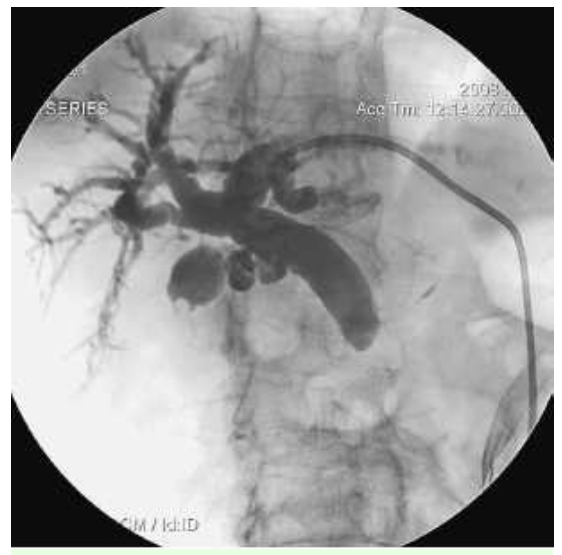

Fig. 3 Percutaneous cholangiogram confirmed complete obstruction of the mid common bile duct.

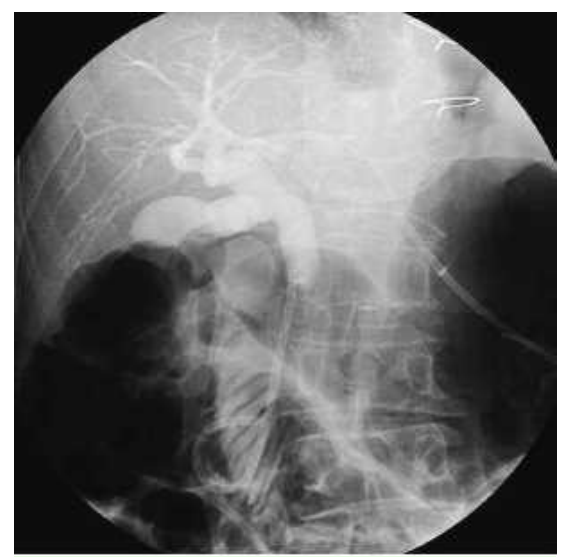

Fig. 6 A 10-Fr plastic stent was inserted to bridge the duct.
Fig. 4 A triple-lumen needle knife was introduced intraductally with the tip pointed against the thin wall of the complete obstruction of the common duct.

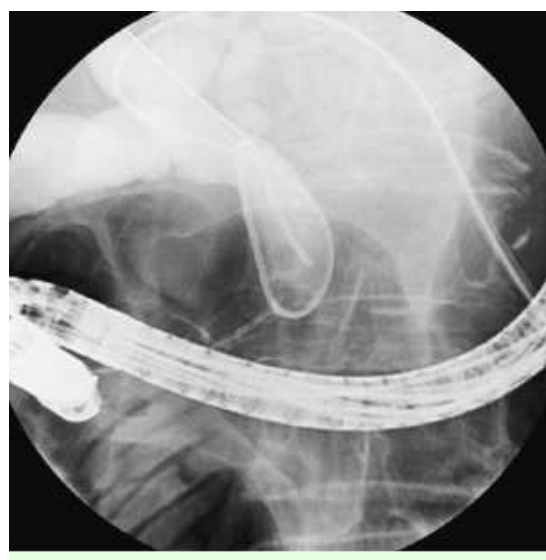

Fig. 5 A puncture was successfully made into the upstream disconnected duct. 
doscopic rendezvous can be performed under endoscopic ultrasound guidance through the duodenum or stomach [4]. Blind puncture of the biliary tract without definite bulging or endoscopic ultrasound confirmation is prone to inadvertent perforation. However, in our case in which a very thin gap was noted by bidirectional cholangiogram, the proximal cholangiogram was used as a landmark for a successful puncture.

Endoscopy_UCTN_Code_TTT_1AR_2AI

R. Rerknimitr ${ }^{1}$, N. Geratikornsupuk ${ }^{1}$, A. Janchai ${ }^{2}$, P. Kullavanijaya ${ }^{1}$

1 Division of Gastroenterology, Department of Internal Medicine, Faculty of Medicine, Chulalongkorn University, Bangkok, Thailand

2 Division of Interventional Radiology, Department of Radiology, Faculty of Medicine, Chulalongkorn University, Bangkok, Thailand

\section{References}

1 Wallace M, Middlebrook M. Percutaneous biliary reconstruction: a report of two cases utilizing "blunt" recanalization and "rendezvous" techniques. Cardiovasc Intervent Radiol 2001; 24: 339-342

2 Dowsett JF, Vaira D, Hatfield AR et al. Endoscopic biliary therapy using the combined percutaneous and endoscopic technique. Gastroenterology 1989; 96: 1180-1186

3 Kahaleh M, Wang P, Shami VM et al. EUSguided transhepatic cholangiography: report of 6 cases. Gastrointest Endosc 2005 61: 307-313

4 Bories E, Pesenti C, Caillol F et al. Transgastric endoscopic ultrasonography-guided biliary drainage: results of a pilot study. Endoscopy 2007; 39: $287-291$
Bibliography

DOI $10.1055 / \mathrm{s}-2008-1077525$

Endoscopy 2008; 40: E242 -E243

(c) Georg Thieme Verlag KG Stuttgart · New York . ISSN 0013-726X

\section{Corresponding author}

\section{Rungsun Rerknimitr, MD}

Division of Gastroenterology, Department of Internal Medicine, Faculty of Medicine Chulalongkorn University

Bangkok 10310

Thailand

Fax: + 66-2-2527839

Rungsun@pol.net 